\title{
ИНТЕЛЛИГЕНЦИЯ В СИСТЕМЕ ГЕГЕМОНИИ АНТОНИо ГРАМШИ
}

\begin{abstract}
В.А. Копылов
Практически все социально-философские теории, рассматривавшие проблемы организации общества, рано или поздно выходили на вопрос социальной структуризации и пытались выделить социальные общности, способные выступить в роли основной структурообразующей единицы социума. Даже руссоизм с его идентитарностью, марксизм с его эгалитаризмом и другие подобные теории были вынуждены, пусть в качестве временной меры, но выделять и анализировать ту или иную социальную группу, играющую руководящую роль. Достаточно часто, со времен Платона и Конфуция, эта роль отводилась наиболее интеллектуально продвинутой группе. Неслучайно она в последствии и была названа интеллигенцией или интеллектуалами. На наш взгляд, проблематика, связанная с этой группой, сохраняет актуальность и в наше время, в том числе в тех социально-экономических и политических условиях, в которых находится современное украинское общество.

Теоретическое наследие Антонио Грамши в этом контексте имеет особое значение, поскольку, с одной стороны, он внес огромный вклад в теорию интеллигенции, с другой стороны, его неомарксизм, на наш взгляд, наиболее близок социальным условиям нашего времени, ну и с третьей стороны, в отечественной философской мысли наследие Грамши по-прежнему во многом остается terra incognita, хотя в западной философии уже давно говорят о грамшилогии как о сложившемся самостоятельном философском направлении. Задачей данной статьи является определение места и роли интеллигенции в системе гегемонии Грамши, что позволит выйти на понимание более широкого вопроса -
\end{abstract}

Актуальні проблеми духовності

(Відп. ред.: Я.В. Шрамко)

Кривий Ріг (2006), 114-126 
экспликации диалектики знания и власти в философии Грамши и неомарксизме XX века.

Учение о гегемонии занимает в общей социально-философской концепции Грамши, пожалуй, центральное место. Заимствовав, как он сам признает, само понятие гегемонии из работ В.И.Ленина [1, с. 56-57], Грамши, на наш взгляд, не только значительно расширил, но и видоизменил его. Показательно, например, что Грамши последовательно ведет речь именно о «полной гегемонии», отличая, таким образом, ленинскую теорию политической, т.е. неполной гегемонии, от своей полной, проявляющейся во всех областях, и прежде всего в интеллектуальной и моральной.

Концептуально Грамши тесно связывает гегемонию с властью и господством. И если нет достаточных оснований для утверждения о том, что Грамши отождествляет эти понятия, то вполне, на наш взгляд, можно утверждать, что он рассматривает их как однопорядковые. Гегемония включает в себя как бы две стороны: во-первых, насилие, отождествляемое с принуждением и, во-вторых, согласие, отождествляемое с убеждением. Взаимопроникая и взаимодополняя друг друга, они и конституируют феномен власти. Формой же проявления, реализации власти выступает господство. Конкретно-историческая характеристика господства производна от тех процессов, которые преобладают в тот или иной период в политическом, гражданском и экономическом обществах. Политическое общество функционально связано с принуждением, а институционально - с государством, гражданское, соответственно, - с убеждением и добровольными общественными организациями.

Раскрывая содержание понятия господства-власти-гегемонии, Грамши идет значительно дальше своих современников-он расширяет его содержание от классического чисто «политэкономического» до этико-политического и интеллектуально-идеологического. Конечно, он не отрицает, что в основе гегемонии всегда лежит преобладание класса или социальной группы в сфере производственных отношений [2, с. 149-150]. Но, по мнению Грамши, для «полной гегемонии» одного этого преобладания совершенно недостаточно. Необходимо еще господство и идеологическое, мировоззренческое, культурное - без этого гегемония невозможна даже при наличии у господствующего класса доступа к политической власти, к силе. Так, главным конструктивным элементом гегемонии становится не только производство, сила, право, а знание и мораль.

Окончательным аккордом видоизменения концепции гегемонии для Грамши становится характеристика ее как отношения педагоги- 
ческого. Отношение гегемонии, по мнению Грамши, всегда оказывается отношением педагогическим, причем таким, при котором и ученик получает основополагающие знания и умения от учителя, и учитель «учится» у ученика, вырабатывая верную стратегию воспитания и руководства $[1$, с. 50]. Такие взаимоотношения существуют во всем обществе - «между слоями интеллигентскими и неинтеллигентсткими, между правящими и управляемыми, между элитой и последователями, между руководителями и руководимыми, между авангардом и основными силами». (Кстати говоря, именно в этом месте Грамши открыто отождествляет интеллигенцию с элитой. Напомним, что это понятие так и не получило в марксизме положительной интерпретации, хотя в это время на Западе уже создавалась теория элит усилиями все тех же итальянцев Г. Моска и В.Паретто). Более того, они обнаруживаются не только внутри одной нации, между составляющими ее силами, но и в международном и мировом масштабе: «между комплексами национальных и континентальных цивилизаций» [1, с. 50]. Здесь также всегда присутствует гегемония и ее «педагогическая составляющая», как например, в отношениях между универсальной европейской культурой и культурой других, неуниверсальных цивилизаций Азии, Африки и Америки [1, с. 133-134]. Политическое господство Запада неотделимо от его идеологического, научного и культурного преобладания, так или иначе признанного практически всеми народами.

Таким образом, сознательное выдвижение Грамши в центр конструкции гегемонии знания логично должно приводить к тому, что классом-гегемоном или группой-гегемоном может и должен стать только тот, кто в наибольшей мере (хотя вполне может быть, что и в любой форме) опирается на знание. Поэтому класс, оказывающий наибольшее влияние на формирование мировоззрения, становится основным претендентом на гегемонию, а сама борьба за нее заключается едва ли не прежде всего в «формировании умов», в создании и распространении идей и учений, которые бы могли подняться на уровень «веры» и разбудить человеческую активность. Однако Грамши почему-то не доводит свои меритократические, как бы мы это назвали сегодня, рассуждения до адекватных, меритократических выводов. Ему не удается окончательно разорвать оковы марксистско-ленинской парадигмы, в частности учения о «всемирно-исторической миссии пролетариата» и обслуживающей, промежуточной, прослоечной роли интеллигенции (или же, что вполне, на наш взгляд, возможно, он просто не хочет этого демонстрировать).

Как бы не подвергая открытому сомнению «священный вопрос» о 
гегемонии пролетариата, а фактически, на наш взгляд, игнорируя этот вопрос, поскольку он никак не вписывался в его теорию, Грамши, по всей видимости сознательно, уходит к другому вопросу - какие социальные силы могут и должны обеспечивать гегемонию господствующего класса, в данном случае пролетариата, во всей ее полноте? Нам представляется, что такой сюжетный поворот Грамши не является чем-то абсолютно новым, в истории мировой философии так поступали достаточно часто - когда не следовало по тем или иным причинам обсуждать того, кто находится на троне, научная и политическая мысль концентрировалась на тех, кто сосредотачивался вокруг трона и обосновывала принадлежность именно им фактически главных социальных функций по организации общества. Такая исследовательская традиция началась, на наш взгляд, еще с Конфуция, достаточно вспомнить его императора - отца народа, осуществляющего, главным образом, связь с небом, и окружающих его дзюн-дзы, реализующих непосредственные функции управления, функции власти. Эта традиция дошла до предшественника Грамши Макса Вебера и отразилась в его теории рациональной бюрократии. Ее и продолжил Грамши в своей теории интеллигенции и гегемонии.

Итак, поскольку гегемония - феномен прежде всего «этико-политический», идеологический и даже педагогический, т.е. в ее основе лежит, как мы это видели, прежде всего знание, то ответ здесь совершенно однозначен - такой силой может быть только интеллигенция. Именно она, в силу обладания необходимым знанием, исполняет роль организатора и руководителя любой социальной группы, и она же ведет ее к гегемонии и поддерживает эту гегемонию впоследствии. «Человеческая масса, - пишет Грамши, - не может «отделиться» и стать независимой сама собой, не организуясь (в широком смысле), а организация невозможна без интеллигенции, то есть без организаторов и руководителей, иначе говоря, теоретический аспект единства «теорияпрактика» должен обособиться в виде слоя лиц, «специализирующихся на концептуальной и философской деятельности» [1, с. 35].

Поставив таким образом интеллигенцию, как главного носителя знания, в основу социальной организации общества в целом и гегемонии в частности, Грамши формирует свое, достаточно оригинальное понимание этой, теперь уже действительно важнейшей социальной группы. Прежде всего он дистанцируется от широко распространенного как в его время, так и поныне понимания интеллигенции, которое он называет «обычным» или «узким» и, естественно, подвергает его жесткой критике. Грамши неоднократно подчеркивал, что традицион- 
ное представление об интеллигентах, как об обособленной прослойке лиц интеллектуального труда, совершенно неприемлемо. Он считает, что интеллигенция не может быть выделена из общества в отдельную группу только на том основании, что ее представители занимаются преимущественно интеллектуальной деятельностью. А именно этот признак и по сегодняшний день является доминирующим в самых различных теориях интеллигенции. Грамши исходит из того, что границы между этой деятельностью и «нервно-мускульными усилиями» весьма расплывчаты и неопределенны. Отделить homo sapiens от homo faber невозможно [1, с.343]. Существуют разные ступени специализации интеллектуальной активности, и где именно «начинается интеллигенция» четко определить нельзя. Следовательно, фактически каждый человек в процессе своей работы прибегает к интеллектуальным усилиям (связанным, например, с технологическими навыками), а за пределами производственной деятельности выступает в роли философа, ценителя искусства, носителя определенной идеологии, мировоззрения и т.д. [1, с. 330-343].

На таком основании можно было бы утверждать, что все люди являются интеллигентами, но не все они в действительности выполняют в обществе функции интеллигентов, точно также, «как о том, кто жарит себе яичницу или пришивает себе заплату на куртку, не скажут, что он является поваром или портным» [1, с. 330]. Поэтому, по твердому убеждению Грамши, интеллигенция должна выделяться в отдельную общность не на основании причастности к интеллектуальному труду, а на основании функций, которые эта прослойка выполняет в общей системе социальных отношений. Таким образом, главным группообразующим критерием становится место и роль в обществе, внешние социальные связи, функции, а не внутренние субъективные характеристики.

Интеллигенция, по мнению Грамши, не образует единый обособленный класс или хотя бы целостную социальную группу, как считали многие его современники и более поздние исследователи. Поскольку интеллигенция, по мнению Грамши, порождается другими классами и функционирует исключительно в тесной взаимосвязи с ними, не имея самостоятельной и самодостаточной функциональной природы, то ее целостность разрывается этими социальными связями. Именно эти социально-классовые тяготения и образуют главную социальную дифференциацию внутри достаточно аморфного образования, называемого интеллигенцией, ее собственная строгость, организованность формируется именно во взаимодействии с теми или иными классами, а не са- 
мостоятельно и самодостаточно. «Не существует независимого класса интеллигентов, - говорит Грамши, - каждая социальная группа обладает собственной прослойкой интеллигентов или стремится создать ее» [3, с. 331]. Рождаясь «на исходной почве существенной функции в мире экономического производства», тот или иной класс или группа «органически создают себе один или несколько слоев интеллигенции, которые придают ей однородность и сознание ее собственной роли не только в экономике, но и в социальной и политической области» [1, c. 327].

Таким образом, интеллигенция в представлении Грамши - это не просто лица интеллектуального труда, а специализированные категории людей, выполняющие организационно-идеологические функции в связи с деятельностью различных классов и социальных групп. Следовательно, интеллигенция как бы по самому своему замыслу призвана обслуживать (т.е. объяснять, направлять и руководить) те или иные социальные классы. Причем, и для нас это особенно важно, обслуживание - главная роль интеллигенции - состоит не в том, чтобы просто ретранслировать идеи класса-гегемона к классам второго уровня. В этом случае интеллигенция лишалась бы самостоятельной, самодостаточной роли, именно таковой она представлялась в классическом марксизме-ленинизме. Сверхзадача и призвание интеллигенции, по Грамши, заключались в том, чтобы обеспечивать идеями класс-гегемон и все другие слои общества, т.е. агрегировать и артикулировать эти идеи. А это уже и есть, на наш взгляд, самостоятельное место во власти. Хотя место и роль различных групп интеллигенции оказываются, естественно, разными.

Исходя из собственного понимания сущности интеллигенции, Грамши строит собственную и весьма оригинальную классификацию с четко определенными критериями, главным среди которых выступает опять же связь с классом и качество самого этого класса. Он исходит из того, что в каждой точке времени и пространства не все интеллигенты непосредственно связаны с существующими и доминирующими в настоящий момент классами. Значительная их часть принадлежит к интеллектуальным прослойкам, которые сохранились от прошлого, то есть были порождены социальными группами, которые уже лишились гегемонии, потеряли прежнее значение или вообще исчезли. «Надстроечный компонент», созданный интеллигенцией этих групп, был настолько существенным, что позволил ей сохраниться несмотря на все изменения характера гегемонии и базиса. Такие категории интеллигенции укоренены в многовековой культурной традиции, и само 
их существование воплощает непрерывность культурного и исторического развития нации. Подобную интеллигенцию, представленную прежде всего церковнослужителями, но также и академическими учеными и философами, Грамши называет «традиционной», отличая ее от «органической» интеллигенции, созданной современными господствующими классами, гегемоном [1, с.328-329].

Интеллигенты подобного рода, объединенные особым «корпоративным духом», четко чувствуют свою историческую преемственность и свои особые качества. Поэтому они считают себя совершенно самостоятельными и самоценными, независимыми от современных политических реалий и господствующей социальной группы. Однако в действительности это иллюзия, которая лежит в основе «независимости церкви», научного академизма и философского идеализма [1, с. 329]. «Традиционная» интеллигенция в любом случае включается в систему социальных отношений и подчиняется гегемонии, ибо в противном случае она не может существовать в обществе. Более того, каждая новая социальная группа, стремящаяся к установлению собственного господства, сразу же начинает бороться за ассимиляцию и «идеологическое завоевание» традиционной интеллигенции, и этот процесс протекает тем быстрее, чем быстрее эта группа формирует свою собственную органическую интеллигенцию $[1$, с. 330-331]. Ускорению подобных тенденций способствует то обстоятельство, что органическая интеллигенция класса, который наиболее активно борется за гегемонию, всегда обладает огромной силой притяжения как для традиционной интеллигенции, так и для большей части общества [3, с.331]. Это позволяет интеллигенции наиболее прогрессивной группы подчинить себе не только традиционных интеллигентов, но и интеллигенцию других социальных групп, и занять главенствующее положение в среде лиц интеллектуального труда.

Отношения различных групп интеллигенции к «миру производства» и системе власти, по словам Грамши, отнюдь не так же непосредственны как отношения связанных с ними классов и других социальных групп. Эти отношения опосредованы сложной социальной тканью и всем комплексом надстроек. Различные слои интеллигенции с разной степенью «органичности» связаны со «своими» группами и, зачастую, в большей степени зависят от господствующей группы, чем от породившего их класса. В целом же интеллигентов различных групп объединяет то, что все они, независимо от происхождения и положения в обществе, исполняют роль «функционеров надстроек» [1, с. 332]. Именно это и есть главный качество-образуюший признак дан- 
ной группы - интеллигенции.

«Комплекс надстроек», которому они служат, весьма сложен, но в нем можно четко выделить два основных «этажа» - этаж «гражданского общества», т.е. совокупности организаций, называемых «частными», и этаж «политического общества или государства», которым соответствует функция гегемонии господствующей группы, функция «прямого господства» или командования, выражающаяся в деятельности государства и законного правительства. Эти функции являются организационными и связующими для всего общества, их и призваны осуществлять интеллигенты. По этому поводу Грамши говорит следующее: «Интеллигенты служат «приказчиками» господствующей группы, используемыми для осуществления подчиненных функций социальной гегемонии и политического управления, а именно: 1) для обеспечения «спонтанного» согласия широких масс населения с тем направлением социальной жизни, которое задано основной господствующей группой, - согласия, которое «исторически» порождается престижем господствующей группы (и, следовательно, оказываемым ей доверием), обусловленным ее положением и ее функцией в мире производства; 2) для приведения в действие государственного аппарата принуждения, «законно» обеспечивающего дисциплину тех групп, которые не «выражают согласия» ни активно, ни пассивно» [1, с.332-333]. Таким образом, интеллигенция, в представлении Грамши, обеспечивает стабильное функционирование государства «в расширенном понимании» («диктатура + гегемония»), т.е. фактически именно интеллигенция реализует на практике гегемонию господствующей группы, хотя «технически» некоторые ее слои примыкают к другим социальным группам или же считают себя независимыми.

Такое понимание функций интеллигенции приводит к существенному расширению этой социальной группы. Грамши включает в нее не только ученых, литераторов, художников, учителей, инженеров, врачей, церковнослужителей, но и всех чиновников, администраторов, менеджеров, клерков, армейских офицеров и т.д., то есть всех тех, кто обеспечивает бесперебойную работу государственного аппарата и институтов гражданского общества $[4$, с. 165$]$. Внутри этого огромного комплекса существует сложная градация по принципу участия различных категорий интеллигентов в управлении и по характеру этого управленческого труда.

Таким образом, Грамши формирует как бы второй план классификации интеллигенции. На этом основании значительная часть интеллигенции, как правило, большая ее часть оказываются просто испол- 
нителями решений господствующей группы и высшей интеллигенции, их Грамши называет «скромными администраторами и распространителями уже существующих, ранее накопленньх интеллектуальных богатств» [1, с.333], естественно, он располагает их на низшей ступени социальной организации. Наиболее же важной, высшей с точки зрения «внутреннего содержания интеллектуальной деятельности», по его мнению, следует признать творческих работников в области различных наук, философии, искусства. Нетрудно заметить, что именно эти группы наиболее тесно связаны с основными знаниевыми системамимировоззрением, идеологией, философией, наукой - которые и формируют полную гегемонию того или иного класса. Именно их роль во власти оказывается главенствующей.

По мнению Грамши, западная демократическо-бюрократическая социальная система создала такую внушительную массу интеллигентов, что существование многих из них не оправдывается «общественными потребностями производства». Оно необходимо лишь для политических нужд основной господствующей группы, причем не столько для нужд управления, сколько для интеллектуальной поддержки этой группы в массах. Формирование столь многочисленной интеллигенции привело к частичному падению ее престижа, к стандартизации индивидов и их интеллектуального труда и породило все те же явления, что и в других «стандартизованных массах»: конкуренцию, безработицу, школьное перепроизводство, эмиграцию, психологическую деградацию и т.д. [1, с. 333-334]. Знания всей этой интеллигенции далеко не в полной мере востребованы властью - ей необходим лишь сам факт существования столь многочисленной «интеллектуальной прослойки». Фактически Грамши, на наш взгляд, предвидел некоторые черты «массового» общества, общества «массовой культуры» середины-второй половины XX века, когда особая роль интеллигенции действительно начала нивелироваться.

Более всего Грамши, конечно, волновал вопрос о роли интеллигенции в формировании новых общественных классов и утверждении их гегемонии. Интеллигенция, как уже отмечалось, способствует выделению некоей общности людей в особую социальную группу, формирует ее самосознание, помогает ей сформулировать собственные интересы, а затем установить союз с другими классами и «инкорпорировать» их интересы в рамках единой идеологии. Эти задачи возлагаются обычно на высшую прослойку интеллигенции - творческую элиту - теоретиков и идеологов нового класса. Другие слои интеллигенции, находящиеся под влиянием высшей прослойки, призваны распространять идеи 
в массах и поддерживать связь между населением и элитой господствующей группы. Как показал Грамши в работе «Некоторые аспекты южного вопроса», именно таким образом осуществлялась гегемония буржуазии и земельной аристократии в Южной Италии, причем «цементировали» все это «здание господства» буржуазные философы-идеологи Б. Кроче и Дж. Фортунатто [3, с. 240-255]. Подобным же образом, по мнению Грамши, следовало действовать и пролетариату в борьбе за построение социалистического общества.

Главная задача в этой области - это создание интеллигенции нового типа, которая бы могла организовано вести рабочий класс к союзу с другими классами и завоеванию гегемонии. Такой тип интеллигента должен формироваться на основе технически образованного специалиста, тесно связанного с производством и пролетариатом. Деятельность «нового интеллигента», по твердому убеждению Грамши, не может сводится к ораторству, но должна заключаться в активном слиянии с практической жизнью в качестве строителя, организатора, непрерывно «убеждающего делом», и, тем не менее, возвышающегося «над абстрактно-математическим духом». «От техники-труда, - говорит Грамши,- необходимо двигаться к технике-науке и к историческому гуманистическому мировоззрению, без которого остается только „специалист“ и не происходит становления „руководителя“ (специалиста плюс политика)» $[1$, с. 344]. Здесь в значительной степени чувствуется, на наш взгляд, влияние времени - эпоха индустриализации, и новых философских теорий - в первую очередь технократизма, что в последствии получило развитие во многих теориях от Д. Бернхейма и Й. Шумпетера до Д. Гелбрейта и Д. Белла.

Задачу формирования новой органической интеллигенции для любого современного класса и, особенно, для пролетариата, Грамши возлагает на политическую партию. Для некоторых социальных групп партия является единственным средством выработки собственной органической интеллигенции на уровне политики и философии, т.е. высшего слоя интеллигенции [1, с. 335]. Помимо этого для всех социальных групп политические партии выполняют в гражданском обществе ту же функцию, которую в политическом обществе выполняет государство - забота об укреплении связей между органической интеллигенцией господствующей группы и традиционной интеллигенцией, причем выполняют ее более эффективно, чем государство, ибо, вступив в партию, «традиционный интеллигент» ассимилируется с органической интеллигенцией данной группы и постепенно сам становится ее частью [1, с. 336]. 
В целом же, задача партии - подготовка «квалифицированных политических интеллигентов», руководителей, организаторов всех видов деятельности и функций, присущих органическому развитию интегрального общества, гражданского и политического. Партии производят индивидуальный отбор из активной массы, который происходит взаимосвязано как в области практической, так и в области теоретической, и имеет своей целью интеграцию теории с практикой для утверждения гегемонии своей группы. «Можно сказать,-замечает Грамши, - что партии вырабатывают новые интеллекты, цельные и всеохватывающие, то есть являются тем тиглем, в котором теория сплавляется воедино с практикой, понимаемой как реальный исторический процесс» $[1$, с. 36$]$. Они создают социальную элиту, у которой новое мировоззрение социальной группы уже стало «стройным и систематическим актуальным сознанием, четкой и решительной волей», что позволяет ей руководить всей экономически активной массой людей поноваторски, постепенно донося это новаторство до «низов». Все члены партии, независимо от их места в партийной иерархии, причастны к этой элите и выступают в роли организаторов и воспитателей широких масс. Поэтому все члены партии могут считаться интеллигентами, ведь они, даже оставаясь членами своих социальньх групп, выполняют в гражданском обществе функции интеллигенции $[1$, с. 336]. Более того, они преодолевают свою сословно-корпоративную замкнутость, выходят на новый уровень исторического развития и, как и все интеллигенты, становятся участниками общей культурной и политической деятельности как в национальном, так и в интернациональном масштабе [1, с.337]. Участие в политической партии, таким образом, не только приобщает человека к власти и гегемонии, но и делает его интеллигентом и даже в определенной мере «творцом истории».

Важнейшей задачей любой группы интеллигенции, в представлении Грамши, является поддержание постоянного единства с народными массами, ибо без этого она теряет свои руководящие функции и не может в полной мере исполнить свою историческую роль в рамках породившей ее социальной группы, нации и всего человечества. Духовный разрыв между интеллигенцией и народом не позволяет распространяться новым политическим идеологиям, философским учениям, прогрессивным идеям, и не дает осуществиться гегемонии самых различных социальных групп, разрушая идеологическое единство «исторического блока» [1, с. 30-31]. Католическая церковь, например, прекрасно осознавая этот факт, всегда предпринимала усиленные меры для того, чтобы не допустить возникновения двух отдельных ре- 
лигий - «религии интеллигенции» и «религии народа», и с помощью политики поддерживала единство верующих на «среднем интеллектуальном уровне» $[1$, с. $31-32]$.

Глубокий разрыв между интеллигенцией и народом, по словам Грамши, всегда был важнейшей проблемой для итальянского общества. Истоки этого разрыва уходят еще во времена Римской империи, но особенно явственно он обозначился с началом эпохи Возрождения и в Новое время. Отличаясь исключительным космополитизмом, итальянская интеллигенция внесла огромный вклад в развитие мировой культуры, но не смогла занять присущие ей руководящие позиции в самом итальянском обществе [1, с.337-338, 357-358,365-377]. Поэтому гегемония итальянской буржуазии, путь к установлению которой был открыт в XIX столетии, так никогда и не смогла осуществиться в полной мере, вследствие чего Италия пошла по весьма отсталому пути развития, приведшему в конечном итоге к установлению фашизма [5, c.68-75], [6, с.44-69]. Аналогичные процессы наблюдались и в других странах, например, в Германии. В то же время во Франции интеллигенция всегда развивалась в гармонии с остальными социальными силами и производственными отношениями, что привело эту страну к поразительному культурному и политическому развитию в XIX - начале XX столетия [1, с.338-340]. Свои особенности во взаимоотношениях между интеллигенцией и господствующими социальными группами и интеллигенцией и народом Грамши обнаруживает и в других государствах (Англии, США, России, Испании, странах Востока), показывая при этом как эти взаимоотношения повлияли на политическое развитие указанных государств [1, с. 337-342, 401-429]. На наш взгляд, данные выводы Грамши очень интересны и для украинского общества. При всем собственном патриотизме, с одной стороны, и понимании условности исторических аналогий, с другой, можно, на наш взгляд, отметить некоторую близость социальной судьбы итальянской интеллигенции и народа с украинской интеллигенцией и народом, что кроме всего прочего еще раз свидетельствует об актуальности обращения к творческому наследию Грамши.

Таким образом, на наш взгляд, есть все необходимые и достаточные основания утверждать, что Грамши фактически создает свою собственную концепцию гегемонии (хотя формально он на это не претендует и позиционирует себя в рамках марксистско-ленинской парадигмы). Главным отличительным и вместе с тем атрибутивным признаком его концепции является выдвижение в центр всей конструкции категории знания; гегемония, таким образом, становится характери- 
стикой не столько политэкономической, сколько нравственно-политической и интеллектуально-идеологической. А отсюда вполне логично следует обоснование в качестве главной социальной силы гегемонии именно интеллигенции - единственной группы, которая по своей профессиональной природе исключительно связана с формированием и передачей знания и культуры. Хотя, по формальному мнению Грамши, она не становится единоличным и самодостаточным гегемоном, а только создает и обеспечивает гегемонию пролетариата. Так, именно интеллигенция становится главным гегемоном, а следовательно, и власть-образующей социальной группой. Грамши развеял и до сих пор очень популярный миф о «политической нейтральности» интеллигенции и четко выявил ее место в структуре власти и господства, поставив под сомнение сам факт существования независимой прослойки лиц интеллектуального труда. Весьма интересно и показательно, что идеи Грамши о месте и роли интеллигенции в системе гегемонии и власти получили мощное применение и развитие в последующей социальной философии. Его концепция гегемонии послужила отправной точкой для разработки теории «третьего» («эксплицитного») лица власти в американской политологии. Исследования положения интеллигенции в системе власти и ее отношения с господствующими классами были продолжены в 50-90 гг. в десятках фундаментальных работ западных исследователей и вдохновили, в частности, М. Фуко на создание нового учения о сущности власти.

\section{1 Литература}

[1] Грамии А. Тюремные тетради. В 3 ч. Ч. 1.- М., 1991.

[2] Грамши А. Избранные произведения. В 3-х т.- М., 1957-1959.Т. 3: Тюремные тетради.

[3] Грамши А. Избранные произведения. - М., 1980.

[4] Грамии А. Избранные произведения. В 3-х т.-М., 1957-1959.Т. 2: Письма из тюрьмы.

[5] Грецкий М.Н. Антонио Грамши - политик и философ.-M., 1991.

[6] Григоръева И.В. Исторические взгляды Антонио Грамши.-М., 1978. 